\title{
Spontaneous closure of an incidental high-flow paravertebral arteriovenous fistula caused by vertebral giant cell tumor curettage: illustrative case
}

\author{
Yen-Heng Lin, MD, MS, ${ }^{1}$ Yu-Cheng Huang, MD, ${ }^{1}$ and Fon-Yih Tsuang, MD, PhD ${ }^{2}$ \\ ${ }^{1}$ Department of Medical Imaging and ${ }^{2}$ Dvision of Neurosurgery, Department of Surgery, National Taiwan University Hospital, Taipei City, Taiwan
}

BACKGROUND Paravertebral arteriovenous fistula (AVF) after spinal surgery is rarely reported in the literature. Its natural course is largely unknown. OBSERVATIONS The authors report a 31-year-old woman with a high-flow AVF after T12 vertebral giant cell tumor curettage. Eight months after the initial surgery, revision en bloc surgery was planned. Preoperative computed tomography angiography was performed for vascularity assessment, which incidentally revealed a large paravertebral early-enhanced venous sac. High-flow AVF was confirmed through subsequent spinal angiography. Endovascular embolization was scheduled before the surgery to avoid massive blood loss. However, the AVF closed spontaneously 1 month after the spinal angiography. The plan was changed to preoperative embolization; subsequently, three-level en bloc spondylectomy was performed smoothly.

LESSONS latrogenic AVF is possible, prompting investigation by vascular imaging when suspected. Embolization is a preferred treatment method when feasible. However, for iatrogenic etiology, the prothrombotic property of the contrast medium may induce the resolution. Multidisciplinary discussion can be very helpful before aggressive spinal surgery.

https://thejns.org/doi/abs/10.3171/CASE2116

KEYWORDS paravertebral arteriovenous fistula; spinal surgery; spontaneous regression; giant cell tumor; total en bloc spondylectomy

Spinal arteriovenous fistulas (AVFs) are a group of uncommon disorders. ${ }^{1}$ Classification is based on the location and pathophysiology of the fistula. ${ }^{2}$ They are subdivided into intradural and extradural lesions. However, symptoms are mostly associated with perimedullary venous drainage in addition to fistula location. ${ }^{3}$ In symptomatic patients, progressive disease may result in congestive or compressive myelopathy or hemorrhage, which indicates that treatment is essential. In asymptomatic patients, diagnosis is usually difficult and treatment controversial. Nevertheless, the natural course of the disease is unclear.

We present a case with high-flow paravertebral AVF that developed after an intralesional curettage surgery for vertebral giant cell tumor and was initially observed through spinal computed tomography angiography (CTA). It occluded spontaneously 1 month after spinal angiography, and subsequent revision en bloc spondylectomy was performed uneventfully.

\section{Illustrative Case}

A 31-year-old woman was diagnosed with a T12 vertebral giant cell tumor with initial presentation of back pain and claudication (Fig. $1 \mathrm{~A}$ and B). She underwent subtotal intralesional tumor curettage and reconstruction with an expandable metallic cage 8 months after diagnosis. The operation was smooth and uneventful. No massive hemorrhage or vascular injury was documented during the first operation. During the follow-up period 8 months after the first operation, evident progression of the residual tumor was observed through magnetic resonance imaging (Fig. 1C). She was referred to our hospital for revision surgery. Her back pain was persistent, but weakness or urinary or fecal incontinence was not observed. No obvious neurological deficit was observed, except for upper motor neuron signs at the bilateral lower limbs.

Because revision surgery was considered, dual-energy CTA of the thoracic spine was performed to assess for osseous alignment and tumor vascularity. ${ }^{4}$ The study revealed a paravertebral dilated pouch with intense early enhancement, which suggested an arteriovenous shunting disease (Fig. 1D). To elucidate its angioarchitecture, spinal angiography was performed. The results of angiography confirmed numerous dilated, tortuous arterial feeders from the left $T 11, T 12, L 1$, and L2 proximal segmental arteries and di-

ABBREVIATIONS AVF = arteriovenous fistula; CTA = computed tomography angiography . INCLUDE WHEN CITING Published May 3, 2021; DOI: 10.3171/CASE2116.

SUBMITTED January 8, 2021. ACCEPTED February 15, 2021.

(c) 2021 The authors, CC BY-NC-ND 4.0 (http://creativecommons.org/licenses/by-nc-nd/4.0/). 

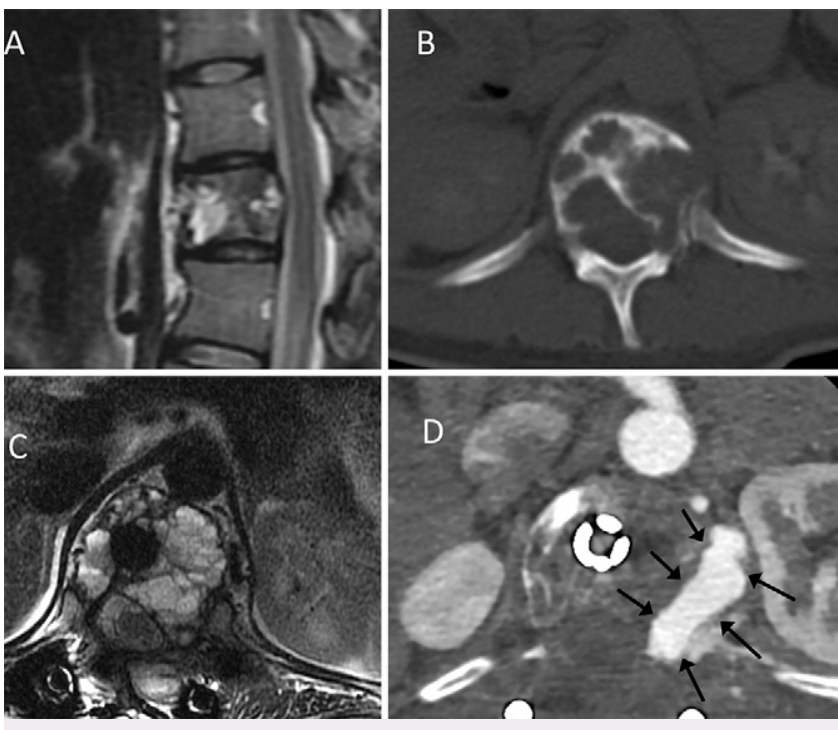

FIG. 1. Preoperative and follow-up studies of the first operation. A: Sagittal T2-weighted magnetic resonance imaging (MRI) showing an expansible heterogeneous osseous tumor in the T12 vertebral body, consistent with a giant cell tumor. B: Axial CTA revealing multifocal osteolytic change of the lesion confined in the vertebral body. C: Postoperative axial T2-weighted MRI showing the cage with susceptibility artifact at the center of the T12 vertebral body. The residual lesion with aneurysmal bone cyst change was evident. D: Axial thinsection CTA revealing an avidly enhancing structure (black arrows) at the left paravertebral area, which suggested a venous sac with shunting.

lated, early-opacified venous pouch, draining into the hemiazygos vein (Fig. 2). After multidisciplinary discussion, endovascular embolization was performed before further revisional total en bloc spondylectomy.

One month after spinal angiography, the patient received general anesthesia for the planned AVF embolization. However, repeated spinal angiography revealed complete resolution of the lesion. Furthermore, an angiographic examination revealed an Adamkiewicz artery from the left L1 lumbar artery, which had not been found in a prior study (Fig. 3A and B). The plan was then changed to preoperative embolization for the tumor. Moreover, repeated CTA confirmed complete obliteration of the venous pouch (Fig. 3C). The operation was performed 3 days after the embolization. Three-level en bloc vertebrectomy from T11 to L1 was then performed without catastrophic hemorrhage (Fig. 4). During the surgery, bilateral segmental arteries from $T 11$ to $L 1$, including the left L1 lumbar artery supplying the Adamkiewicz artery, were ligated. The patient recovered from the operation smoothly without neurological deficit and was followed up in the clinic.

\section{Discussion}

\section{Observations}

Isolated paravertebral AVF is an uncommon spinal vascular disorder. Unlike spinal arteriovenous metameric syndrome, it is not associated with intradural AVF or arteriovenous malformation. ${ }^{5}$ In our angiographic study, the feeding arteries arose from the proximal
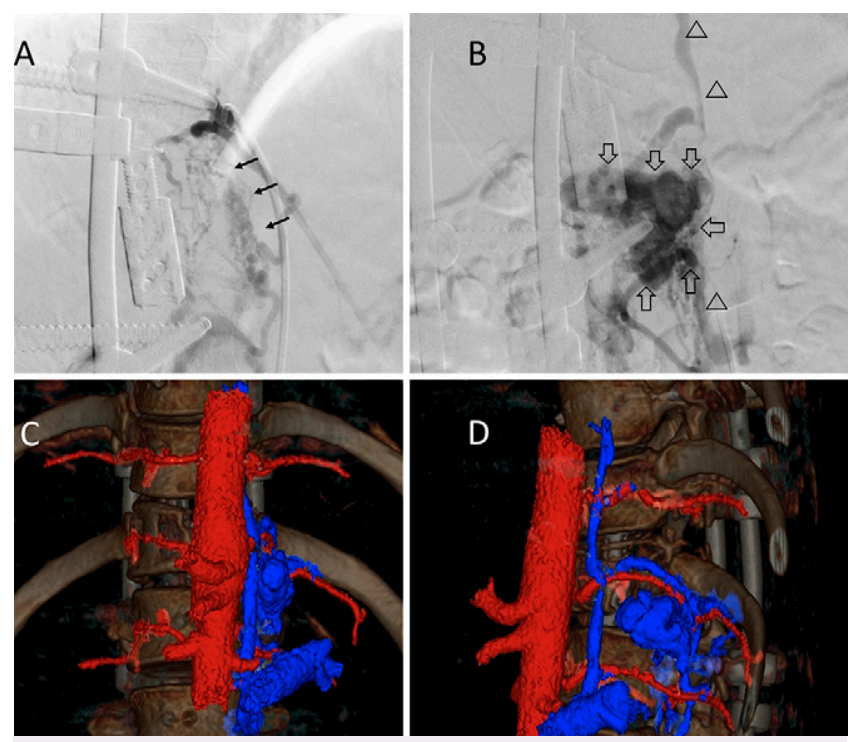

FIG. 2. Radiological illustration of the paravertebral AVF. A: Early arterial phase of left T11 segmental angiogram showing numerous tortuous feeding arteries (black arrows). B: Venous phase of left T11 segmental angiogram showing a dilated venous sac (open arrows) and drainage toward the hemiazygos vein (open arrowheads). C and D: Frontal and lateral views of the threedimensional volume rendering of CTA. Manual segmentation of arterial (red) and venous (blue) structures was performed. The venous sac was considerably engorged and extended from the T11 to L1 paravertebral area. segmental arteries of four levels, and the fistula drained into the paravertebral vein directly. Therefore, the fistula location was paravertebral rather than epidural. ${ }^{6}$ No perimedullary drainage, congestive myelopathy, or compressive myelopathy was observed. Because of its location and presentation, it was considered as iatrogenic in nature. AVF in our patient was incidentally found because we routinely use spine CTA as a preoperative evaluation tool for en bloc spondylectomy even in revision surgery. Therefore, the indication for the treatment was to avoid uncontrolled bleeding during the revision surgery. The AVF closed spontaneously during the followup period.

Spontaneous occlusion of cerebral AVF has been occasionally observed. ${ }^{7,8}$ Similarly, reports of spinal AVF regression have been found in the literature., ${ }^{9,10}$ This phenomenon has been reported to be facilitated after hemorrhage, angiography, or even cesarean section. ${ }^{11-13}$ Kang et al. reported seven cases of low-flow spinal AVF that occluded spontaneously, and they summarized previously reported cases. ${ }^{14}$ They postulated that the prothrombotic property of nonionic contrast medium may be a significant contributing factor. Furthermore, the thrombosis of the paravertebral venous pouch (Fig. 3C) may have caused the spontaneous occlusion. Because we performed extensive spinal angiography with multiple sessions of injections to clarify the angioarchitecture of the fistula, it might have caused the thrombosis of the venous sac. However, previously reported cases were all of the low-flow type, and our case had a relatively high-flow shunt with arterial feeders from four adjacent 

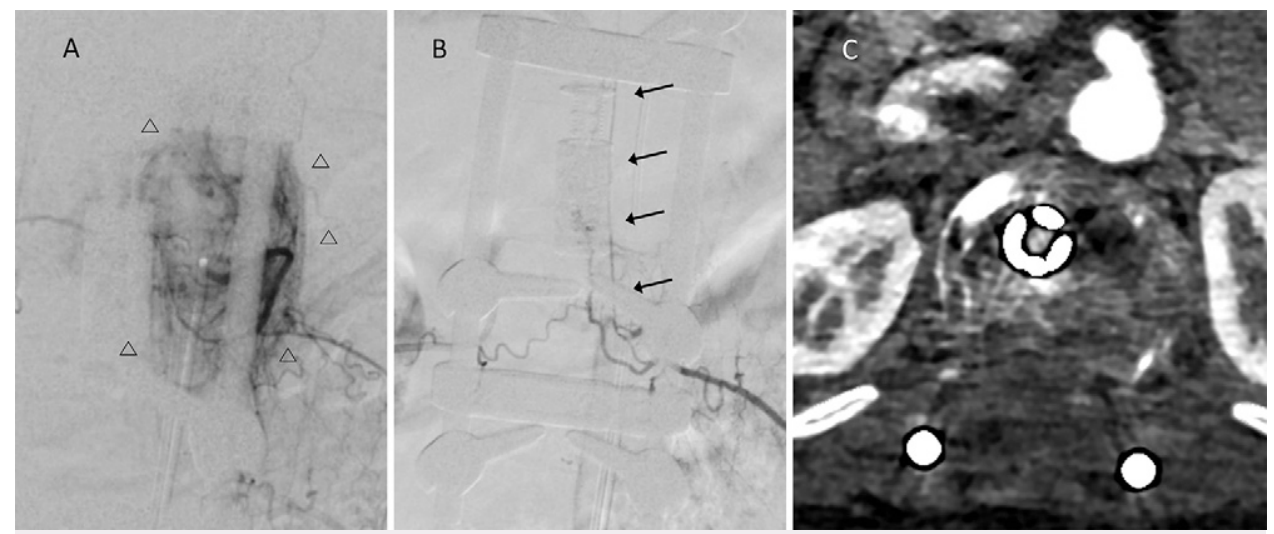

FIG. 3. Frontal view of spinal angiography before scheduled endovascular embolization. A: Late arterial phase of left T12 segmental angiogram showing complete obliteration of AVF. Tumor blush (open arrowheads) is clearly shown. B: Early arterial phase of left $\mathrm{L} 1$ segmental angiogram showing Adamkiewicz artery (black arrows) from this level, which was not seen in the prior study because of shunting flow. C: Axial thin-section CTA confirmed complete obliteration of the venous sac. The adjacent hemiazygos vein was also not dilated.

levels of segmental arteries; hence, spontaneous closure was unexpected.

latrogenic AVF after spinal surgeries mostly occurred in iliac or vertebral $A \mathrm{VF}^{15}{ }^{15}$ latrogenic and traumatic spinal AVFs were less common and have been reported in stabbing injury, spinal surgery, or even spinal anesthesia. ${ }^{16-19}$ Symptoms were usually due to perimedullary drainage, and treatment was usually through embolization. For posttraumatic AVF, Torok et al. reported a case of spontaneous occlusion of epidural AVF after stabbing injury. ${ }^{20}$ This low-flow shunt lesion caused myelopathy because of perimedullary venous drainage. The incidence rate and etiology of asymptomatic iatrogenic spinal AVF are largely unknown, although a traumatic lesion has been suggested to be likely to occlude spontaneously. ${ }^{9,21}$
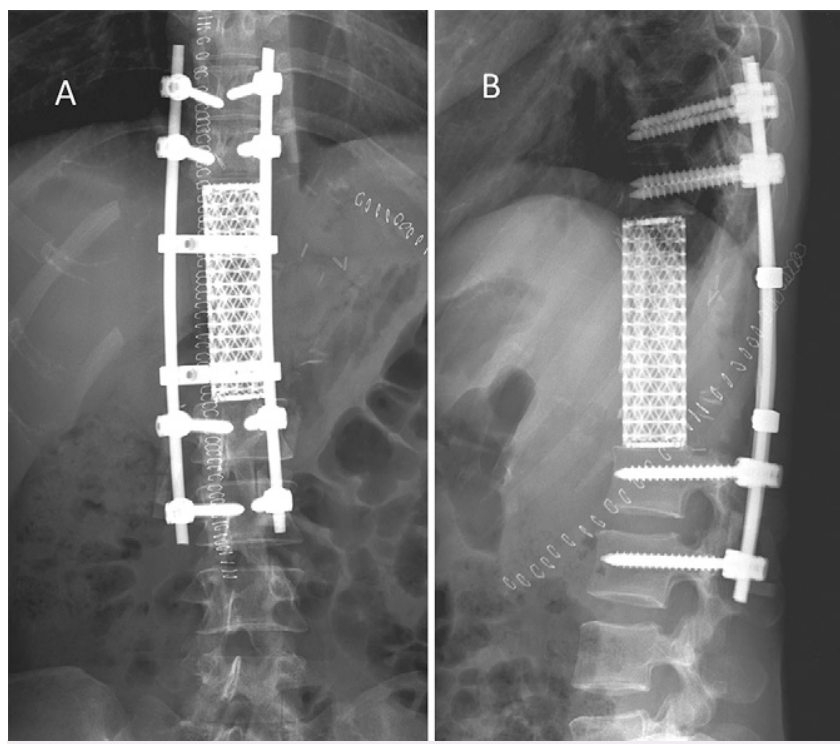

FIG. 4. A and B: Frontal and lateral thoracic spine radiographs after revisional three-level en bloc spondylectomy from $\mathrm{T} 11$ to $\mathrm{L} 1$. The patient recovered smoothly after the surgery without any neurological deficit.
In our case, because the tissue plane of the AVF had been altered after the prior surgery, its vessel wall integrity may not have been robust, making it more likely to be thrombosed after exposure to a high concentration of contrast medium. Therefore, spontaneous occlusion occurred rapidly after angiography.

\section{Lessons}

latrogenic paravertebral AVF after spinal surgery is rare but can be detected through spinal CTA. Embolization is usually warranted. However, spontaneous occlusion is possible even in a high-flow lesion. Multidisciplinary discussion for treatment planning is essential before aggressive spinal surgery.

\section{References}

1. Ozpinar A, Weiner GM, Ducruet AF. Epidemiology, clinical presentation, diagnostic evaluation, and prognosis of spinal arteriovenous malformations. Handb Clin Neurol. 2017;143:145-152.

2. Spetzler RF, Detwiler PW, Riina HA, Porter RW. Modified classification of spinal cord vascular lesions. J Neurosurg. 2002;96 (2 suppl):145-156.

3. Kiyosue H, Matsumaru Y, Niimi Y, et al. Angiographic and clinical characteristics of thoracolumbar spinal epidural and dural arteriovenous fistulas. Stroke. 2017;48(12):3215-3222.

4. Huang YC, Tsuang FY, Lee CW, et al. Assessing vascularity of osseous spinal metastases with dual-energy CT-DSA: a pilot study compared with catheter angiography. AJNR Am J Neuroradiol. 2019;40(5):920-925.

5. Niimi Y, Uchiyama N, Elijovich L, Berenstein A. Spinal arteriovenous metameric syndrome: clinical manifestations and endovascular management. AJNR Am J Neuroradiol. 2013;34(2):457-463.

6. Kiyosue H, Tanoue S, Okahara M, et al. Spinal ventral epidural arteriovenous fistulas of the lumbar spine: angioarchitecture and endovascular treatment. Neuroradiology. 2013;55(3):327-336.

7. Luciani A, Houdart E, Mounayer C, et al. Spontaneous closure of dural arteriovenous fistulas: report of three cases and review of the literature. AJNR Am J Neuroradiol. 2001;22(5):992-996.

8. Krapf H, Siekmann R, Freudenstein D, et al. Spontaneous occlusion of a cerebral arteriovenous malformation: angiography and MR imaging follow-up and review of the literature. AJNR Am J Neuroradiol. 2001;22(8):1556-1560. 
9. Meder JF, Devaux B, Merland JJ, Frédy D. Spontaneous disappearance of a spinal dural arteriovenous fistula. AJNR Am J Neuroradiol. 1995;16(10):2058-2062.

10. Panciani PP, Fontanella M, Crobeddu E, et al. Spontaneous occlusion of a spinal arteriovenous malformation: is treatment always necessary? J Neurosurg Spine. 2010;12(4):397-401.

11. Kinoshita M, Asai A, Komeda S, et al. Spontaneous regression of a spinal extradural arteriovenous fistula after delivery by cesarean section. Neurol Med Chir (Tokyo). 2009;49(7):313-315.

12. Chun JY, Gulati M, Halbach V, Lawton MT. Thrombosis of a spinal arteriovenous malformation after hemorrhage: case report. Surg Neurol. 2004;61(1):92-94.

13. Aydin K, Sencer S, Sencer A, et al. Angiography-induced closure of perimedullary spinal arteriovenous fistula. Br J Radiol. 2004;77 (923):969-973.

14. Kang J, Gregg L, Gailloud P. Spontaneous resolution of low-flow spinal arteriovenous fistulas. Neuroradiology. 2017;59(10):1003-1012.

15. Gok M, Aydin E, Guneyli S, et al. latrogenic vascular injuries due to spinal surgeries: endovascular perspective. Turk Neurosurg. 2018;28(3):469-473.

16. Bai $Y, Z$ Zhi $X$, Jian F, et al. Traumatic spinal perimedullary arteriovenous fistula due to knife stabbing and subsequent kyphosis: case report. J Neurosurg Spine. 2013;19(2):222-225.

17. Murakami T, Nakagawa I, Wada T, et al. Lumbar spinal epidural arteriovenous fistula with perimedullary venous drainage after endoscopic lumbar surgery. Interv Neuroradiol. 2015;21(2):249-254.

18. Baltsavias G, Argyrakis N, Matis GK, Mpata-Tshibemba S. Spinal arteriovenous fistula with progressive paraplegia after spinal anaesthesia. J Korean Neurosurg Soc. 2014;55(2):106-109.
19. Ogita S, Endo T, Inoue T, et al. Traumatic spinal perimedullary arteriovenous fistula induced by a cervical glass stab injury. World Neurosurg. 2016;96:610.e9-610.e13.

20. Torok C, Laufer I, Gailloud P. Spontaneous resolution of a thoracic spinal epidural arteriovenous fistula caused by stabbing injury. Spine (Phila Pa). 2013;38(11):E683-E686.

21. Olutola PS, Eliam M, Molot M, Talalla A. Spontaneous regression of a dural arteriovenous malformation. Neurosurgery. 1983;12(6): 687-690.

\section{Disclosures}

The authors report no conflict of interest concerning the materials or methods used in this study or the findings specified in this paper.

\section{Author Contributions}

Conception and design: Lin. Acquisition of data: all authors. Analysis and interpretation of data: Huang. Drafting the article: Lin. Critically revising the article: Tsuang. Reviewed submitted version of manuscript: Tsuang, Lin. Approved the final version of the manuscript on behalf of all authors: Tsuang. Administrative/technical/material support: Tsuang, Huang.

\section{Correspondence}

Fon-Yih Tsuang: National Taiwan University Hospital, Taipei City, Taiwan. tsuangfy@gmail.com; tsuangfy@ntu.edu.tw. 